\title{
A VIDA SOCIAL DAS PANC: UM ESTUDO ETNOGRÁFICO EM FEIRAS ECOLÓGICAS DE PORTO ALEGRE
}

\author{
Renata Tomaz do Amaral Ribeiro ${ }^{1}$ \\ Renata Menasche ${ }^{2}$
}

\section{Introdução}

É sabido que as Plantas Alimentícias Não Convencionais - PANC $^{3}$ (Kinupp; Lorenzi, 2014) têm sido estudadas por diferentes áreas do conhecimento, como biologia, agronomia, nutrição, entre outras. Além disso, tem-se percebido que essas plantas estão presentes em programas de televisão e em vídeos no YouTube, bem como em espaços que refletem sobre alimentação, saúde, bem-estar ou biodiversidade.

O Grupo Viveiros Comunitários (GVC), sediado no Instituto de Biociências da Universidade Federal do Rio Grande do Sul (UFRGS), por exemplo, tem estimulado discussões sobre PANC, promovendo atividades educacionais em que essas plantas são identificadas e são elaborados cardápios que as incluem. Na cartilha Plantas Alimentícias Não Convencionais (PANC): hortaliças espontâneas e nativas (Becker et al., 2015), além de catalogar plantas que não haviam sido classificadas por Kinupp e Lonrenzi (2014), o grupo traz receitas que informam, inclusive, as propriedades nutricionais e medicinais das PANC. Ranieri et al. (2017), no mesmo sentido, por meio do Projeto Viva a Agroecologia, desenvolveram uma cartilha de identificação na qual apontam que as PANC devem ser avaliadas segundo a biodiversidade de cada território, na intenção de explorar ao máximo

1 Universidade Federal do Rio Grande do Sul, Brasil. Email: re.t.ribeiro@gmail.com

ORCID id: https://orcid.org/0000-0002-2598-0207

2 Universidade Federal do Rio Grande do Sul, Brasil. Email: renata.menasche@gmail.com

ORCID id: https://orcid.org/0000-0002-8707-6037

3 PANC é o acrônimo para Plantas Alimentícias Não Convencionais. Apesar do uso corriqueiro da expressão PANCs, o uso formalmente adequado é PANC (Kinupp; Lorenzi, 2014). As PANC são todas as plantas e partes delas que são consideradas comestíveis, mas não são convencionalmente consumidas e comercializadas. Podem ser: "raízes tuberosas, tubérculos, bulbos, rizomas, cormos, talos, folhas, brotos, flores, frutos e sementes ou ainda látex, resina e goma, ou indiretamente quando são usadas para obtenção de óleos e gorduras alimentícios. Inclui-se neste conceito também as especiarias, substâncias condimentares e aromáticas, assim como plantas que são utilizadas como substitutas do sal, bem como edulcorantes (adoçantes), amaciantes de carnes, corantes alimentícios e aquelas utilizadas no fabrico de bebidas, tonificante e infusões" (Kinupp; Lorenzi, 2014: 13).

Iluminuras, Porto Alegre, v. 20, n. 51, p. 263-277, dezembro, 2019. 
sua potencialidade, visto que todos os territórios possuem uma diversidade de PANC, conforme observam. Por outro lado, do ponto de vista da Nutrição, Paschoal et al. (2016) defendem que as PANC se enquadram no contexto das dietas sustentáveis, constituindo parte importante da agrobiodiversidade.

Desse modo, a difusão de conhecimentos em torno das PANC expandiu-se bastante no último período, ultrapassando os muros das universidades. Em Porto Alegre, não são raras as atividades envolvendo essas plantas, abrangendo desde feiras de mudas e sementes a caminhadas guiadas (por agricultores, estudantes, pesquisadores), com o intuito de identificação das PANC em diferentes localidades do município.

Nesse processo de popularização, algumas delas tornaram-se emblemáticas, não por serem consideradas mais PANC que outras, mas por guardarem uma ambiguidade: ser ou não ser PANC. Isso porque, a depender do contexto, não são consideradas apenas plantas, mas sim comida, fazendo parte da culinária de um determinado grupo social, como é o caso do pisacan (Taraxacum officinale), planta consumida tradicional e cotidianamente entre as famílias rurais de Ipê, município situado na região da serra gaúcha. Assim como o pisacan, outras plantas consideradas PANC pela ciência, mas que em Ipê e no extremo sul de Porto Alegre são de uso tradicional e/ou cotidiano, têm sua comercialização intensificada nas feiras estudadas. Nessas feiras, as PANC protagonizam muitas das histórias narradas por agricultores.

Conforme sugere Appadurai (2008), são os sujeitos humanos que qualificam as coisas, ou seja, que possuem o poder de significar o mundo ao seu redor. Mas, de um ponto de vista metodológico, é a circulação das coisas que revela o contexto social em que estão inseridas. Desse modo, podemos considerar que algumas das PANC, ao se deslocarem da mesa das famílias rurais para as feiras ecológicas e dessas para a mesa dos consumidores, além de evidenciarem o contexto de complementariedade entre o campo e a cidade, também elucidam determinados contextos, práticas, visões de mundo e formas de organização do real.

\section{De comida a PANC, de PANC a comida}


Os contextos rurais são dinâmicos (possuem diferentes atividades produtivas), sendo distintos entre eles e também com relação aos urbanos. Desse modo, neste estudo compreende-se o rural e o urbano não como espaços geográficos distintos e em posições dicotômicas, mas sim como espaços que possuem suas próprias construções sociais, onde os sujeitos compartilham representações. É nessa perspectiva que, há aproximadamente dois anos, tem sido realizada pesquisa etnográfica nas feiras ecológicas do Bom Fim e da Tristeza, em Porto Alegre, onde são comercializados alimentos de famílias rurais de Ipê e do extremo sul da capital gaúcha, entre outras. O método etnográfico, conforme sugere Oliveira (1996), está alicerçado em olhar, ouvir e escrever, buscando, nesse processo, apreender o outro (suas práticas, costumes, visão de mundo) como alteridade. Deste modo, para este estudo, foram realizadas, pela primeira autora deste artigo, imersões em campo nas quais, em um convívio prolongado, estabeleceu-se uma relação (embasada em confiança e ética) com os sujeitos interlocutores da pesquisa (Victora et al., 2000). Foram, então, utilizadas uma série de técnicas associadas ao método etnográfico: observação participante, entrevistas abertas e diários de campo.

A inserção em campo da pesquisadora ocorreu por intermédio de uma amiga que, há algum tempo, trabalha com uma família rural do município de Ipê que comercializa seus produtos nas duas feiras estudadas. A amiga da pesquisadora, historiadora e também militante da Agroecologia, apresentou-a àquela família feirante com o intuito de que preenchesse uma vaga de auxiliar de banca. Assim, sem previamente ter a intenção de realizar um estudo etnográfico, passou a trabalhar, em janeiro de 2017, nessas feiras ecológicas aos sábados, de forma revezada — isto é, alternando a cada semana a feira em que estaria presente. Não demorou muito para perceber que ali existia a possibilidade de um interessante campo. Foi então que revelou aos agricultores ser cientista social e estudante de pós-graduação em Desenvolvimento Rural na UFRGS e que gostaria de desenvolver um estudo contando com sua parceria. A família prontamente concordou com a pesquisa, assim como as demais famílias que conheceu ao longo do campo realizado nas feiras, no período de julho de 2017 a agosto de 2019.

No decorrer da experiência etnográfica, tornou-se cada vez mais evidente que o rural e o urbano são interdependentes e que se relacionam de forma complementar, em trocas materiais e simbólicas, sendo essas objetivadas nas feiras, evidenciando-se a 
constante inter-relação humana com as coisas e com outros sujeitos. Nesse sentido, esta pesquisa busca concentrar-se na movimentação das PANC, tendo em vista que a circulação das mercadorias/coisas (neste caso, das PANC) possibilita apreender a vida social que possuem, conforme sugere Appadurai (2008).

Mas antes de desenvolver o argumento, cabe apresentar, ainda que de forma sucinta, as feiras em questão. Genericamente, as feiras ecológicas são espaços públicos de interação cultural e comercial que buscam garantir o acesso da população a produtos agroecológicos de qualidade e oriundos da agricultura familiar. A Resolução da Secretaria Municipal da Produção, Indústria e Comércio - SMIC no 3, de 26 de dezembro de 2012, disciplina a realização de todas as feiras ecológicas no município de Porto Alegre, sendo o Conselho das Feiras Ecológicas responsável por complementar os casos omissos da resolução supracitada. Apesar de, em Porto Alegre, as feiras ecológicas serem regidas pelas mesmas legislações, são espaços específicos, possuindo características únicas, dinâmicas e organizações próprias. Nas feiras do Bom Fim e da Tristeza é possível perceber uma gama de aspectos que as distinguem, tornando-as singulares. Na Tristeza, os alagamentos; no Bom Fim, o pouco espaço; em cada uma delas, o modo como se realizam a circulação de pessoas ou as práticas de solidariedade... Enfim, são diferentes formas de organização, o que torna as feiras únicas. Do mesmo modo, assim como encontramos essa diversidade nas feiras, os interlocutores deste estudo mostram, através de suas falas, a multiplicidade de "universos" constituídos pelos territórios rurais de Ipê e do extremo sul de Porto Alegre.

Os agricultores de Ipê possuem laços profundos com o território em que vivem, são descendentes de imigrantes italianos, consideram-se colonos e compartilham representações simbólicas e sociais como, por exemplo, a língua praticada no local, uma variação do italiano. Nas falas desses sujeitos, é comum escutar afirmações que sugerem o orgulho do pertencimento à colônia. Nas feiras do Bom Fim e da Tristeza, não é raro observar o encontro entre o colono que vive no campo e aquele que migrou para a cidade. Esse último busca encontrar na feira um pouco daquilo que um dia vivenciou na colônia: as conversas e piadas (que apenas os colonos compreendem), as receitas e sabores compartilhados em suas narrativas. Conforme Machado et al. (2015: 116), "no sul do Brasil, reconhecem-se e são conhecidos como colonos os agricultores descendentes de imigrantes europeus, para quem essa identidade se converte em símbolo de diferenciação 
étnica". Esses sujeitos possuem, portanto, uma identidade coletiva em torno de símbolos locais que, no caso, remetem a uma italianidade da colônia: o vinho ${ }^{4}$, a massa da nonna ${ }^{5}$, a polenta com radicci ${ }^{6}$, o agnoline com $\mathrm{crem}^{7}$, o pisacan cotti (cozido) ou com polenta ${ }^{8}$. Afinal, como sugere Da Matta (1987), a alimentação revela identidades sociais, uma vez que permite não apenas expressar essas identidades, mas também experimentar aspectos de determinada cultura. Além disso, algumas comidas podem guardar memórias afetivas, dado que, como aponta Mintz (2001), são adultos próximos, como pais e avós, que nos inserem em um sistema culinário. No mesmo sentido, Garine (1987: 3) ensina que "os indivíduos se sentem emocionalmente ligados aos hábitos alimentares de sua infância, em geral marcada pela cultura tradicional".

A produção das famílias rurais de Ipê é diversa e em quantidade; não é à toa que a cidade é considerada a Capital Nacional da Agricultura Ecológica ${ }^{9}$. Segundo site da prefeitura de Ipê (www.ipe-rs.com.br), no Brasil, o município foi o primeiro a produzir orgânicos e atualmente conta com mais de cem famílias que vivem da agricultura de base ecológica. Entre os produtos, esses agricultores trazem algumas das PANC que costumam consumir tradicional e cotidianamente (conforme sazonalidade): pisacan (Taraxacum officinale), batata-crem (Tropaeolum pentaphyllum), quaresma (Annona montana), goiabaserrana (Acca sellowiana), menstruz (Coronopus didymus), araçá (Psidium cattleianum) e amora (Rubus brasiliensis). Também, aquelas plantas que recentemente tiveram seu cultivo adotado: chinesinha (Brassica rapa subsp. chinensis), batata-cará (Dioscorea bulbifera), feijão-olho-de-cabra (Phaseolus lunatus) e alcachofra (Cynara scolymus). Essas últimas plantas passaram a ser cultivadas com a popularização da noção de PANC, sendo que seu potencial como alimento e como mercadoria foi apresentado por outros agricultores,

4 Nas colônias italianas no Sul do país é comum a produção de vinho artesanal.

$5 \quad$ Massa da vovó.

6 A Polenta com radicci é um prato feito à base de farinha de milho e da planta Cichorium intybus, popularmente conhecida nas colônias de origem italiana no Sul do país como radicci.

$7 \quad$ Agnoline é uma massa artesanal recheada com Pien (pasta feita à base de frango e farinha de trigo); já crem é o nome popular da planta Tropaeolum pentaphyllum, consumida tradicionalmente nas colônias de origem italiana no Sul do Brasil e considerada PANC nas feiras ecológicas de Porto Alegre. Portanto, Agnoline com crem é um prato que consiste em uma massa modelada artesanalmente, recheada com Pien e acompanhada de crem.

$8 \quad$ Pisacan Cotti é um prato cozido feito com a planta Taraxacum officinale, conhecida em Ipê como pisacan. Pisacan com polenta, é um refogado com polenta, prato à base de farinha de milho.

$9 \quad$ O título foi promulgado através da lei federal $n^{\circ} 12.238$, de 19 de maio de 2010 . 
também feirantes. Nas feiras, os agricultores contam, em "oficinas informais", como costumam consumir essas plantas em seus cotidianos, conforme registrado no trecho de diário de campo reproduzido abaixo:

\begin{abstract}
Apesar do frio, próximo às $7 \mathrm{~h}$ da manhã já havia uma pequena circulação de consumidores na feira do Bom Fim. A geada estava baixa, o que, conforme uma agricultora, anunciava um dia ensolarado. Uma moça (com aproximadamente vinte e poucos anos) aproximou-se da banca, olhou para os produtos sobre a mesa, perguntou o preço do molho de tomate e, em seguida, pegou uma batata crem. Aproximou a batata do rosto, como se quisesse sentir o aroma e em seguida perguntou: "é inhame?". O agricultor, que estava sentado sobre as caixas, aproximou-se da moça, pegou a batata na mão e disse: “não, é crem!". “Como?”, perguntou a moça. Olhei ao redor e, além da jovem, mais três pessoas observavam, atentas, a explicação do agricultor: duas senhoras, de aproximadamente sessenta e poucos, e um jovem rapaz com menos de trinta anos. Apesar da agitação da feira, todos atentos e curiosos ouvem a história relatada pelo agricultor. Segundo ele, esta planta é uma raiz forte, portanto tem que ter cuidado na hora de consumir. Observa que, em sua casa, gostam de comer o crem com agnoline. "Não pode faltar crem pra comer com agnoline!". A moça interrompe e pergunta: "mas e como que se faz para comer?". Conforme o agricultor, em sua casa ele prepara em conserva. Descasca o crem e rala, coloca em um pote de vidro, acrescentando metade de água morna e metade de vinagre. Depois é só ir usando aos pouquinhos. Por fim, ele observa que a esposa costuma ralar o crem direto sobre alguns pratos, como a carne assada no forno.
\end{abstract}

Ao revelar como costuma preparar a batata-crem em sua casa, o agricultor revela um pouco de suas práticas e saberes envolvendo o consumo dessa planta, classificada, segundo categorização estabelecida no âmbito das ciências dos alimentos, como PANC, mas que é percebida por ele e sua família como comida tradicional e do cotidiano. Além da crem, outras plantas, como a goiaba-serrana, pisacan, quaresma e menstruz, são compreendidas como PANC (Kinupp; Lorenzi, 2014) por não serem convencionalmente comercializadas e consumidas, ainda que, em Ipê, sejam alimentos utilizados cotidianamente e, até mesmo, como comida tradicional. Assim, a noção de PANC apresenta certa fluidez, conforme os aspectos culturais e sociais de distintos territórios e grupos sociais. Nas feiras estudadas, a circulação dessas plantas evidencia que aquilo que para certos sujeitos e territórios é considerado PANC, não necessariamente o será para outros.

A planta Taraxacum officinale, popularmente conhecida como dente-de-leão, tem ganho bastante evidência em programas de televisão e transmissões do YouTube que discutem saúde e alimentação, bem como nas feiras ecológicas e espaços que se destinam a discussões que tangenciam a temática. Essa planta possui todas as suas partes comestíveis, conforme observou um agricultor de Ipê, feirante do Bom Fim. Ainda segundo ele, "na 
colônia a gente chama de pisacan". Conforme o interlocutor, o pisacan que eles vendem não é o mesmo que se costuma consumir na colônia. Para a comercialização, costumam cultivar; já para o consumo próprio, o mais apreciado é aquele que se "colhe no mato". Parece consenso entre os agricultores interlocutores da pesquisa que aquele pisacan que se busca no mato é mais amargo e preferido por eles. Abaixo, na imagem, uma filha de agricultores mostra, na feira da Tristeza, prato de pisacan feito por ela.

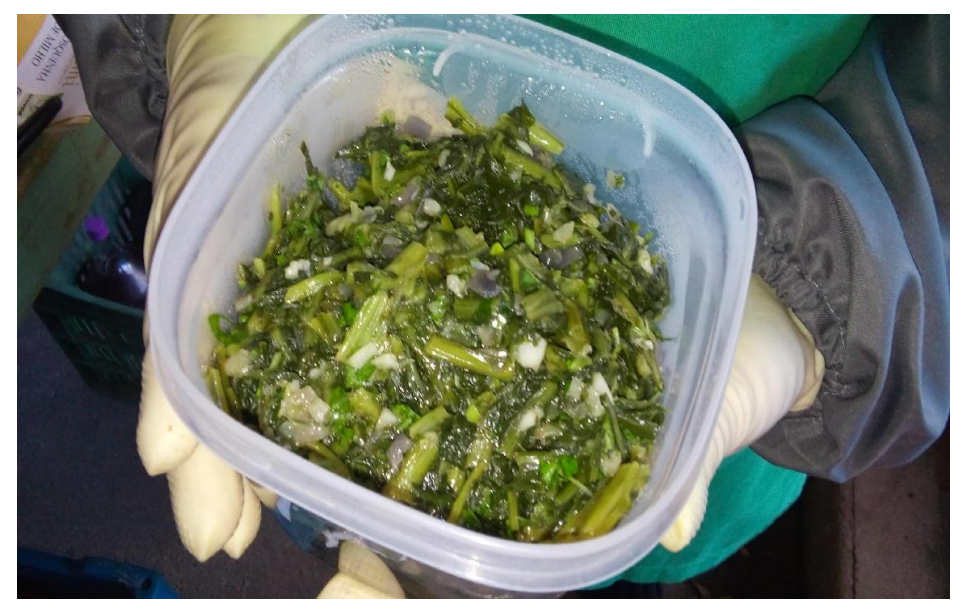

Fonte: Acervo das autoras. Registro realizado durante pesquisa de campo (2018).

Entre as PANC, o pisacan/dente-de-leão é possivelmente uma das plantas mais emblemáticas da categoria, juntamente com a pitaya (Hylocereus undatus) e a ora-pronóbis (Pereskia aculeata), sendo que a última é alimento tradicional em diferentes locais do estado de Minas Gerais. Na cidade mineira de Sabará ocorre anualmente o Festival da Orapro-nóbis, com confecção de pratos tradicionais e festividades em torno da planta. Tal como o pisacan, essas plantas guardam a ambiguidade: ser ou não ser PANC. Pode-se mesmo sugerir que, à medida que mais se evidenciam usos tradicionais e cotidianos (conforme sazonalidade) dessas plantas, essas se tornam mais intensamente emblemáticas da categoria. No entanto, nem por isso são mais facilmente identificadas pelos consumidores, que comumente, na feira, apontam e perguntam: isso é PANC? Ou ainda, como registrado no trecho de diário escrito após campo na feira da Tristeza, reproduzido a seguir: 
Estávamos Noi (agricultora de Ipê) e eu conversando quando uma mulher branca, de aproximadamente sessenta e poucos anos aproximou-se. Com muitas sacolas presas ao braço, a senhora com esforço ergueu a mão, apontando para uma planta sobre a banca e perguntou: "Isso é Pitaya?". Noi olhou para mim com um olhar que guardava certa jocosidade e, em seguida, sorriu para a senhora, respondendo: "Não, isso é quaresma, ariticum". A mulher franziu o rosto, como se fizesse um ponto de interrogação, pegou a quaresma na mão e disse: "queria Pitaya, mas não estou achando. Isso é gostoso?". Então, a Noi pegou uma quaresma e, com as mãos, sem ajuda de faca, abriu a fruta, que já estava bem madura e suculenta, deu uma mordida e, em seguida, cuspiu as sementes. $\mathrm{Na}$ sequência entregou nas mãos da consumidora a outra metade da quaresma e disse para experimentar, mas que tivesse "cuidado com as sementes".

Esse tipo de confusão não é raro, ainda que a pitaya, atualmente, seja encontrada até mesmo em algumas redes de supermercado, sendo uma das PANC mais procuradas nas feiras ecológicas. Os consumidores escutam falar, por meio de fontes diversas, sobre seus benefícios...e vão em busca do fruto; entretanto, não sabem identificá-lo. Além da pitaya, outras PANC são bastante procuradas nas feiras: ora-pro-nóbis, dente-de-leão, capuchinha (Tropaeolum majus), hibisco (Hibiscus sabdariffa).

Assim como os agricultores de Ipê, os do extremo sul de Porto Alegre também possuem práticas e saberes envolvendo o consumo de PANC. Contudo, o território em que vivem corresponde a um espaço mais heterogêneo, onde famílias que possuem práticas tradicionais - que envolvem não apenas o território, mas também o consumo e o cultivo de PANC - convivem com outras, que podemos chamar neorrurais, tendo adotado a vida no campo há aproximadamente 5-20 anos.

Neste estudo, consideramos tradicionais os agricultores que fazem uso ancestral do território; isto é, desde seus antepassados praticam o espaço e constroem conhecimento a partir dele. Esses conhecimentos são passados de mãe para filha, entretanto, não são inalteráveis, pois se transformam ao longo do tempo a partir dos deslocamentos desses sujeitos, que circulam não apenas em seus "mundos", mas também por outros "mundos". Vale aqui lembrar que "a tradição [...] não é o passado que sobrevive no presente, mas o passado que, no presente, constrói as possibilidades do futuro" (Woortmann, 1990: 17). Nesse contexto e a partir da recente visibilidade das PANC, esses agricultores passaram a (re)descobrir algumas das plantas que outrora eram por eles consumidas cotidiana e/ou tradicionalmente, como o dente-de-leão e a ora-pro-nóbis, passando a adotar seu cultivo, consumo e comercialização, bem como o de outras plantas, recentemente apresentadas a eles pelas famílias neorrurais e por profissionais de áreas como agronomia ou biologia. 
Além das plantas já mencionadas, essas famílias rurais costumam, atualmente, nas feiras ecológicas, comercializar beldroega (Portulaca oleracea) e bananinha-do-mato (Bromelia balansae). Conforme aponta um agricultor tradicional do extremo sul de Porto Alegre, a bananinha é muito boa como xarope: basta fazer uma calda, fervendo por um longo período água, açúcar e bananinha. "Fica uma delícia". Segundo ele, quando criança, essa receita era feita por sua avó, e “cura aquele 'ronco' do pulmão". O mesmo interlocutor, em outra oportunidade, compartilhou com consumidores, em "oficina" informal ao redor de sua banca na feira da Tristeza, que a ora-pro-nóbis é ótima em dietas veganas, ajudando até mesmo a emagrecer. Em seguida, explicou como costuma consumir a planta em sua casa, frisando que fica ótimo com galinha caipira, mas também é possível usar no pão, substituindo ovos, ou como couve refogada.

Já os neorrurais, apesar de não possuírem práticas tradicionais em relação ao território, também produzem e disseminam conhecimentos sobre as PANC. Conforme Sastoque (2013), neorrural são os sujeitos que, buscando construir uma vida mais satisfatória e vantajosa em comparação àquela que se vivia na cidade, por diferentes motivos (sejam eles materiais ou subjetivos), decidem de maneira consciente migrar para contextos rurais. Os neorrurais interlocutores desta pesquisa, em sua maioria com formação acadêmica, refletem que a mudança da cidade para o campo está relacionada à busca por uma vida mais saudável e mais conectada com a natureza. Concordamos, neste sentido, com Giuliani (1990: 67), que refletindo sobre os neorrurais observa que:

\begin{abstract}
A volta às relações diretas com a natureza, a ciclos produtivos e tempo de trabalho mais longos e menos rígidos, ao ar puro e à tranquilidade, assim como o desejo de relações sociais mais profundas e, sobretudo, da auto-determinação, são as dimensões que atraem pessoas da cidade ao campo; assim como outrora as luzes da cidade atraíram a população do campo.
\end{abstract}

A produção de PANC desses sujeitos neorrurais acontece há mais de dez anos e está diretamente relacionada ao surgimento da noção proposta por Kinupp (2007). Além de comercializarem e consumirem as PANC, também realizam eventos, "vivências" em suas propriedades rurais, onde essas plantas recebem especial atenção no itinerário percorrido. Dentre as PANC comercializadas por esses sujeitos estão: beldroega, pepininho (Melothria cucumis), hibiscos, capuchinha, feijão-borboleta (Clitoria ternatea), peixinho-da-horta 
(Stachys byzantina), bok choy (Brassica rapa subsp. Chinensis), tomate-de-árvore (Solanum betaceum), melão-de-árvore (Solanum muricatum), bem como produtos processados, como pão de urtiga (Boehmeria caudata) e compota doce e salgada de hibiscos. Do mesmo modo que os agricultores de Ipê e os tradicionais do extremo sul de Porto Alegre, também os neorrurais dessa última região costumam protagonizar "oficinas", que acontecem de maneira informal ao redor das bancas nas feiras estudadas, conforme relatado em trecho de diário de campo abaixo:

O sol já havia nascido e o frio da madrugada dava lugar a uma agradável temperatura naquela linda manhã de sol na feira da Tristeza. [...] Reconheço uma melodia: "samba de uma nota só", de Tom Jobim, que estava sendo lindamente tocada pelo saxofonista que sempre faz a "trilha sonora" da feira. Aproximo-me de uma agricultora neorrural, aproveitando que ainda não havia movimento, e puxo assunto: "Que delícia é poder trabalhar ouvindo..." e ela completa "Tom Jobim". Damos risada, concordando em gestos. Ela me oferece café, prontamente eu aceito; vou à banca em que trabalho e pego a minha caneca. Quando volto, observo que a jovem agricultora já não está mais sozinha, mas conversando com uma mulher (aproximadamente 35 anos), sobre uma das plantinhas que estava sobre a banca. A neorrural, segurando uma pequena caixa de plástico contendo delicadas flores de feijão borboleta, sugere à cliente que elas ficam lindas na decoração de saladas e completa: "Não parecem pequenas vulvas?". A cliente primeiro parece perplexa com o comentário, mas depois demonstra entusiasmo ao pegar as duas últimas caixinhas contendo a planta e dizer, "vou levar". A agricultora, enquanto conta o troco para uma nota de $\mathrm{R} \$ 50,00$, finaliza a conversa observando que daquela florzinha também é possível fazer corante azul. Basta fazer um chá e depois misturá-lo naquilo que se quer tingir: "no glacê do bolo, na panqueca, na massa do pão...", conforme ela sugere.

Por conseguinte, apesar de haver tantos aspectos que distinguem as feiras do Bom Fim e da Tristeza, bem como os sujeitos interlocutores deste estudo, percebemos, a partir das feiras estudadas, que não é raro agricultores protagonizarem "oficinas" informais a respeito de como se prepara e se consome as PANC comercializadas, revelando, em suas falas, práticas e saberes associados ao consumo dessas plantas, que para eles não são PANC, mas sim comida do cotidiano e até mesmo tradicional.

Na sequência, são apresentados três quadros nos quais são especificadas as plantas comestíveis consideradas não convencionais pelas ciências dos alimentos, mas que para essas famílias rurais não o são:

Quadro 1 - Plantas classificadas como PANC, mas que para os agricultores de Ipê não o são 


\begin{tabular}{|c|c|c|}
\hline Nome científico & Nome popular/Local & $\begin{array}{c}\text { Comercialização } \\
\text { nas feiras ecológicas } \\
\text { estudadas }\end{array}$ \\
\hline Amaranthus viridis & Amarantus/Caruru & Não \\
\hline $\begin{array}{l}\text { Campomanesia } \\
\text { xanthocarpa }\end{array}$ & Guabiroba/Guavirova & Não \\
\hline Myrcianthes pungens & Guabiju/Guaviju & Não \\
\hline Acca sellowiana & Goiaba-serrana/Goiaba-serrana & Sim \\
\hline Annona montana & Araticum/Quaresma & Sim \\
\hline Coronopus didymus & Mastrunço/Menstruz & Sim \\
\hline Cynara scolymus & Alcachofra/Alcachofra & Sim \\
\hline Eugenia uniflora & Pitanga/Pitanga & Sim \\
\hline Phaseolus lunatus & $\begin{array}{l}\text { Feijão-olho-de-cabra/Feijão-olho- } \\
\text { de-cabra }\end{array}$ & Sim \\
\hline Psidium cattleianum & Araçá/Araçá & Sim \\
\hline Rubus brasiliensis & Amora/Amora & Sim \\
\hline Taraxacum officinale & Dente-de-leão/Pisacan & Sim \\
\hline $\begin{array}{l}\text { Tropaeolum } \\
\text { pentaphyllum }\end{array}$ & Batata-crem/Batata-crem & Sim \\
\hline
\end{tabular}

Fonte: Elaborado por Renata Ribeiro (2019).

Quadro 2 - Plantas classificadas como PANC, mas que para os agricultores neorrurais do extremo sul de Porto Alegre não o são

\begin{tabular}{|c|c|c|}
\hline Nome científico & Nome popular & $\begin{array}{c}\text { Comercialização } \\
\text { nas feiras ecológicas }\end{array}$ \\
\hline
\end{tabular}




\begin{tabular}{|l|l|c|}
\hline & & estudadas \\
\hline Basella alba & Bertalha & Sim \\
\hline Boehmeria caudata & Urtiga & Sim \\
\hline $\begin{array}{l}\text { Brassica rapa subsp. } \\
\text { Chinensis }\end{array}$ & Bok choy & Sim \\
\hline Clitoria ternatea & Feijão-borboleta \\
\hline Hibiscus sabdariffa & Hibisco & Sim \\
\hline Melothria cucumis & Pepininho & Sim \\
\hline Pereskia aculeata & Ora-pro-nóbis & Sim \\
\hline Physalis pubescens & Fisális & Sim \\
\hline Solanum betaceum & Tomate-de-árvore & Sim \\
\hline Solanum muricatum & Melão-de-árvore & Sim \\
\hline Stachys byzantina & Peixinho-da-horta & Sim \\
\hline Taraxacum officinale & Dente-de-leão & \\
\hline Tropaeolum majus & Capuchinha & \\
\hline
\end{tabular}

Fonte: Elaborado por Renata Ribeiro (2019).

Quadro 3 - Plantas classificadas como PANC, mas que para os agricultores tradicionais do extremo sul de Porto Alegre não o são

\begin{tabular}{|l|l|c|}
\hline \multicolumn{1}{|c|}{ Nome científico } & \multicolumn{1}{|c|}{ Nome popular } & $\begin{array}{c}\text { Comercialização } \\
\text { nas feiras ecológicas estudadas }\end{array}$ \\
\hline Butia & Butiá & Não \\
\hline Basella alba & Bertalha & Sim \\
\hline Bromelia balansae & Bananinha-do-mato & Sim \\
\hline Pereskia aculeata & Ora-pro-nóbis & Sim \\
\hline
\end{tabular}

Iluminuras, Porto Alegre, v. 20, n. 51, p. 263-277, dezembro, 2019. 


\begin{tabular}{|l|l|c|}
\hline Physalis pubescens & Fisális & Sim \\
\hline Portulaca oleracea & Beldroega & Sim \\
\hline Stachys byzantina & Peixinho-da-horta & Sim \\
\hline Taraxacum officinale & Dente-de-leão & Sim \\
\hline
\end{tabular}

Fonte: Elaborado por Renata Ribeiro (2019).

Desse modo, as famílias rurais em questão têm contribuído para o fortalecimento da noção de PANC, porque, ainda que classificadas pelas ciências dos alimentos, são os agricultores que constroem no imaginário dos consumidores das feiras que determinada PANC não é apenas uma planta com potencial nutritivo, mas sim comida. Afinal, como aponta Garine (1987), cada sociedade possui necessidades alimentares distintas, tanto no que se refere à quantidade quanto à qualidade; isto é, aquilo que será escolhido para comer - o que será percebido enquanto comida. Assim, a alimentação não tem apenas como função suprir necessidades biológicas, mas também cumprir com exigências culturais, religiosas, políticas...Porque, como bem aponta Fischler (1995), apesar do ser humano ser um animal onívoro, ele não consome de tudo. O mesmo ocorre com as PANC: defini-las enquanto alimento não as torna comida. É necessário construir a percepção de que essas plantas são mais do que nutritivas, daí o pisacan com polenta feito pela nonna; o crem em conserva que não pode faltar para comer com agnoline; a bananinha do mato - como xarope, além de deliciosa, tira o "ronco" dos pulmões -; ou ainda a ora-pro-nóbis, deliciosa com galinha caipira, mas também é ótima em dietas veganas. Por fim, encerramos esta reflexão com a frase de um agricultor de Ipê que, em entrevista aberta, afirmou, sorrindo: “eu só planto o que eu gosto de comer".

\section{Considerações finais}

Nos últimos anos, as PANC passaram a ter destaque em vários espaços. Com a visibilidade que essas plantas têm recebido, algumas delas passaram a ser percebidas como emblemáticas da categoria, não por se enquadrarem mais do que outras plantas à noção, mas sim porque estão associadas a práticas e saberes cotidianos e tradicionais em diferentes 
contextos sociais e culturais. Assim, algumas dessas plantas que possuem usos tradicionais, como é o caso da ora-pro-nóbis (Pereskia aculeata) e do dente-de-leão, ou pisacan (Taraxacum officinale), quando passam a receber maior atenção, tanto da academia e da mídia como de espaços que discutem saúde, bem-estar e alimentação, passam também a expressar uma ambiguidade: em determinados territórios são PANC; em outros, não. Nesse contexto, agricultores de Ipê e do extremo sul de Porto Alegre intensificam, nas feiras, a comercialização de plantas consideradas PANC pela ciência, mas que são percebidas por essas famílias rurais como comida do cotidiano ou até mesmo tradicional. Vale aqui recordar Fischler (1995), ao observar que sim, os sujeitos humanos, diferentemente de outras espécies, precisam de uma diversidade de fontes de nutrientes para suprir sua necessidade diária de proteínas, vitaminas, minerais, glúcidos e assim por diante, estando justamente por isso submetidos ao paradoxo do onívoro; isto é, a uma tensão entre escolher o alimento que é familiar e o que é desconhecido - uma angústia, por assim dizer, superada quando colocamos em prática a cultura (Fischler, 1995).

Por conseguinte, como sugere Appadurai (2008), a circulação das PANC e sua constituição enquanto mercadoria, ao sair da mesa das famílias rurais para a mesa dos consumidores, revela o contexto social no qual estão inseridas, bem como de que forma os agricultores, interlocutores deste estudo, percebem e se relacionam com essas plantas. Nas feiras ecológicas em questão, apesar da já apontada multiplicidade, percebe-se que são os agricultores que detêm conhecimento sobre as plantas. São eles que podem explicar sobre seus usos, formas de preparo, de consumo e quais benefícios esperar. Assim, podemos dizer que, nas feiras, são os agricultores os mestres, porque são eles que convertem, no imaginário dos consumidores, as PANC em comida, e não a ciência.

\section{REFERÊNCIAS}

APPADURAI, Arjun (org.). A vida social das coisas: as mercadorias sob uma perspectiva cultural. Niterói: Ed. UFF, 2008.

BECKER, Marilia E.; NOUHUYS, Iana S.; KEHL, Lia C.; BRACK, Paulo S. Plantas alimentícias não convencionais (PANCs): hortaliças espontâneas e nativas. In: BECKER, Marilia E. (org.). Plantas alimentícias não convencionais (PANCs): hortaliças espontâneas e nativas. Porto Alegre: Ed. UFRGS, 2015. 
DA MATTA, Roberto. Sobre o simbolismo da comida no Brasil. O Correio da Unesco, Rio de Janeiro, v. 15, n. 7, p. 22-23, 1987.

FISCHLER, Claude. El (h)omnívoro: el gusto, la cocina y el cuerpo. Barcelona: Anagrama, 1995.

GARINE, Igor de. Alimentação, culturas e sociedades. O Correio da Unesco, Rio de Janeiro, v. 15, n. 7. p. 4-7, 1987.

GIULIANI, Gian M. Neoruralismo: O Novo Estilo dos Velhos Modelos. Revista brasileira de Ciências Sociais, São Paulo, v. 5, n. 14, p. 59-67, 1990.

KINUPP, Valdely. Plantas alimentícias não-convencionais da região metropolitana de Porto Alegre, RS. 2007. Tese (Doutorado em Fitotecnia) - Programa de Pós-Graduação em Fitotecnia, Universidade Federal do Rio Grande do Sul, Porto Alegre, 2007.

KINUPP, Valdely; LORENZI, Harri. Plantas Alimentícias Não Convencionais (PANC) no Brasil: guia de identificação, aspectos nutricionais e receitas ilustradas. São Paulo: Instituto Plantarum de Estudos da Flora, 2014.

MACHADO, Carmem J.; MENASCHE, Renata; SALAMONI, Giancarla. Comida, identidade e simbolismo: saberes e práticas alimentares na conformação da italianidade na colônia de Pelotas. In: MENASCHE, Renata (org.). Saberes e sabores da colônia: alimentação e cultura como abordagem para o estudo do rural. Porto Alegre: Ed. UFRGS, 2015.

MINTZ, Sidney W. Comida e antropologia: uma breve revisão. Revista Brasileira de Ciências Sociais, São Paulo, v. 16, n. 47, p. 31-41, 2001.

OLIVEIRA, Roberto C. O trabalho do antropólogo: olhar, ouvir, escrever. Revista de Antropologia (USP), São Paulo, v. 39, n. 1, 1996.

PASCHOAL, Valéria; GOUVEIA, Isabela; SOUZA, Neiva. Plantas Alimentícias Não Convencionais (PANCs): o potencial da biodiversidade brasileira. Revista Brasileira de Nutrição Funcional, São Paulo, v. 33, n. 68, 2016.

RANIERI, Guilherme R.; BORGES, Felipe; NASCIMENTO, Vinicius; GONÇALVES, Juliana R. Guia prático sobre PANCs: Plantas Alimentícias Não Convencionais. Instituto Kairós (org.) São Paulo: Instituto Kairós, 2017.

SASTOQUE, Marlon Javier M. Una Tipología de los Nuevos Habitantes del Campo: aportes para el estudio del fenómeno neorrural a partir del caso de Manizales, Colombia. PiracicabaSP, Vol. 51, Supl. 1, p. 31-48, 2013.

VICTORA, Ceres G.; KNAUTH, Daniela R.; HASSEN, Maria de N. A. Pesquisa qualitativa em saúde: uma introdução ao tema. Porto Alegre: Tomo Editorial, 2000.

WOORTMANN, Klaas. Com parente não se neguceia: o campesinato como ordem moral. Anuário Antropológico, Rio de Janeiro, 87, 1990.

Recebido 17/10/2019

Aprovado 11/12/2019 